\title{
Surface Energy as a Descriptor of Catalytic Activity
}

Houlong Zhuang, ${ }^{\dagger}$ Alexander J. Tkalych,, and Emily A. Carter ${ }^{\S,}$

${ }^{\dagger}$ Department of Mechanical and Aerospace Engineering, Princeton University, Princeton, NJ 08544, USA

${ }^{\ddagger}$ Department of Chemistry, Princeton University, Princeton, NJ 08544, USA

$\S$ School of Engineering and Applied Science, Princeton University, Princeton, NJ 08544, USA

Supporting Information 


\section{Surface energies and Potentials of Zero Charge (PZC) of six common catalysts}

Table S1. Surface energy $E_{\text {surf }}\left(\mathrm{J} / \mathrm{m}^{2}\right)$ in vacuum and in aqueous solution. PZC (V) of six common catalysts calculated with VASP and JDFTx using the same PBEsol functional and lattice constants.

\begin{tabular}{|c|c|c|c|}
\hline & $E_{\text {surf }}^{\text {vac }}$ & $E_{\text {surf }}^{\text {solution }}$ & PZC \\
\hline $\mathrm{Au}$ & $0.976^{\mathrm{a}}$ & $0.981^{\mathrm{a}}$ & $4.99^{\mathrm{a}}$ \\
& $1.051^{\mathrm{b}}$ & $1.049^{\mathrm{b}}$ & $5.04^{\mathrm{b}}$ \\
\hline $\mathrm{Pd}$ & $1.675^{\mathrm{a}}$ & $1.680^{\mathrm{a}}$ & $5.01^{\mathrm{a}}$ \\
& $1.725^{\mathrm{b}}$ & $1.731^{\mathrm{b}}$ & $5.16^{\mathrm{b}}$ \\
\hline $\mathrm{Pt}$ & $1.806^{\mathrm{a}}$ & $1.812^{\mathrm{a}}$ & $5.50^{\mathrm{a}}$ \\
& $1.824^{\mathrm{b}}$ & $1.830^{\mathrm{b}}$ & $5.62^{\mathrm{b}}$ \\
\hline $\mathrm{WC}$ & $3.686^{\mathrm{a}}$ & $3.674^{\mathrm{a}}$ & $4.59^{\mathrm{a}}$ \\
& $3.636^{\mathrm{b}}$ & $3.621^{\mathrm{b}}$ & $4.58^{\mathrm{b}}$ \\
\hline $\mathrm{W}_{2} \mathrm{C}$ & $3.194^{\mathrm{a}}$ & $3.186^{\mathrm{a}}$ & $4.68^{\mathrm{a}}$ \\
& $3.191^{\mathrm{b}}$ & $3.181^{\mathrm{b}}$ & $4.63^{\mathrm{b}}$ \\
\hline $\mathrm{Mo}_{2} \mathrm{C}$ & $3.310^{\mathrm{a}}$ & $3.298^{\mathrm{a}}$ & $4.25^{\mathrm{a}}$ \\
& $3.280^{\mathrm{b}}$ & $3.270^{\mathrm{b}}$ & $4.30^{\mathrm{b}}$ \\
\hline
\end{tabular}

${ }^{\mathrm{a}}$ VASP

b JDFTx 


\section{Stacking sequence, interlayer distance, surface energies and PZC of nine novel catalysts}

Table S2. Stacking sequence, interlayer distance $d(\AA)$, surface energies $E_{\text {surf }}\left(\mathrm{J} / \mathrm{m}^{2}\right)$ in vacuum and in aqueous solution, and PZC (V) of nine hybrid catalysts calculated with VASP and JDFTx using the same PBEsol functional and lattice constants. The interlayer distance is measured between the metal monolayer and the top atomic layer of the transition metal carbide. The subscripts in each stacking sequence refer to various elements in each layer.

\begin{tabular}{|c|c|c|c|c|c|}
\hline & $\begin{array}{c}\text { Stacking } \\
\text { sequence }\end{array}$ & $d$ & $E_{\text {surf }}^{\text {vac }}$ & $E_{\text {surf }}^{\text {solution }}$ & PZC \\
\hline $\mathrm{Au} / \mathrm{WC}$ & $A_{\mathrm{Au}} B \mathrm{~W} A_{\mathrm{C}}$ & 2.248 & $1.241^{\mathrm{a}}$ & $1.245^{\mathrm{a}}$ & $5.09^{\mathrm{a}}$ \\
& & & $1.233^{\mathrm{b}}$ & $1.210^{\mathrm{b}}$ & $5.20^{\mathrm{b}}$ \\
\hline $\mathrm{Pd} / \mathrm{WC}$ & $A_{\mathrm{Pd}} B_{\mathrm{W}} A_{\mathrm{C}}$ & 2.066 & $1.765^{\mathrm{a}}$ & $1.767^{\mathrm{a}}$ & $3.71^{\mathrm{a}}$ \\
& & & $1.837^{\mathrm{b}}$ & $1.837^{\mathrm{b}}$ & $3.79^{\mathrm{b}}$ \\
\hline $\mathrm{Pt} / \mathrm{WC}$ & $A_{\mathrm{Pt}} B_{\mathrm{W}} A_{\mathrm{C}}$ & 2.070 & $2.052^{\mathrm{a}}$ & $2.054^{\mathrm{a}}$ & $4.69^{\mathrm{a}}$ \\
& & & $2.043^{\mathrm{b}}$ & $2.046^{\mathrm{b}}$ & $4.78^{\mathrm{b}}$ \\
\hline $\mathrm{Au} / \mathrm{W}_{2} \mathrm{C}$ & $A_{\mathrm{Au}} B_{\mathrm{W}} A_{\mathrm{C}}$ & 2.189 & $1.208^{\mathrm{a}}$ & $1.212^{\mathrm{a}}$ & $4.49^{\mathrm{a}}$ \\
& & & $1.253^{\mathrm{b}}$ & $1.257^{\mathrm{b}}$ & $4.41^{\mathrm{b}}$ \\
\hline $\mathrm{Pd} / \mathrm{W}_{2} \mathrm{C}$ & $A_{\mathrm{Pd} B \mathrm{~W}} A_{\mathrm{C}}$ & 2.022 & $1.483^{\mathrm{a}}$ & $1.485^{\mathrm{a}}$ & $4.09^{\mathrm{a}}$ \\
& & & $1.545^{\mathrm{b}}$ & $1.549^{\mathrm{b}}$ & $4.17^{\mathrm{b}}$ \\
\hline $\mathrm{Pt} / \mathrm{W}_{2} \mathrm{C}$ & $A_{\mathrm{Pt}} B_{\mathrm{W}} A_{\mathrm{C}}$ & 2.020 & $1.885^{\mathrm{a}}$ & $1.888^{\mathrm{a}}$ & $4.47^{\mathrm{a}}$ \\
& & & $1.871^{\mathrm{b}}$ & $1.877^{\mathrm{b}}$ & $4.51^{\mathrm{b}}$ \\
\hline $\mathrm{Au} / \mathrm{Mo}_{2} \mathrm{C}$ & $A_{\mathrm{Au}} B_{\mathrm{Mo}} A_{\mathrm{C}}$ & 2.191 & $1.143^{\mathrm{a}}$ & $1.147^{\mathrm{a}}$ & $4.28^{\mathrm{a}}$ \\
& & & $1.150^{\mathrm{b}}$ & $1.154^{\mathrm{b}}$ & $4.33^{\mathrm{b}}$ \\
\hline $\mathrm{Pd} / \mathrm{Mo}_{2} \mathrm{C}$ & $A_{\mathrm{Pd} B} B_{\mathrm{Mo}} A_{\mathrm{C}}$ & 2.076 & $1.513^{\mathrm{a}}$ & $1.515^{\mathrm{a}}$ & $4.15^{\mathrm{a}}$ \\
& & & $1.584^{\mathrm{b}}$ & $1.587^{\mathrm{b}}$ & $4.24^{\mathrm{b}}$ \\
\hline $\mathrm{Pt} / \mathrm{Mo}_{2} \mathrm{C}$ & $A_{\mathrm{Pt}} B_{\mathrm{Mo}} A_{\mathrm{C}}$ & 2.055 & $1.809^{\mathrm{a}}$ & $1.811^{\mathrm{a}}$ & $4.54^{\mathrm{a}}$ \\
& & & $1.887^{\mathrm{b}}$ & $1.892^{\mathrm{b}}$ & $4.57^{\mathrm{b}}$ \\
\hline $\mathrm{VASP}$ & & & & \\
\hline
\end{tabular}

${ }^{\mathrm{a}}$ VASP

b JDFTx 


\section{Surface energies of transition metal carbides}

Table S3. Surface energy $\left(\mathrm{J} / \mathrm{m}^{2}\right)$ of $\mathrm{WC}(0001), \mathrm{W}_{2} \mathrm{C}(0001)$, and $\mathrm{Mo}_{2} \mathrm{C}(100)$ in vacuum calculated with the LDA, PBE, and PBEsol exchange-correlation functionals. The lowest energy for each type of surface is in bold.

\begin{tabular}{|c|c|c|c|c|c|}
\hline & & & LDA & PBE & PBEsol \\
\hline \multirow[t]{4}{*}{ WC } & \multirow{2}{*}{$\begin{array}{c}\mathrm{W}- \\
\text { terminated }\end{array}$} & W-rich & 3.804 & 3.353 & 3.686 \\
\hline & & C-rich & 4.343 & 3.561 & 4.103 \\
\hline & \multirow{2}{*}{$\begin{array}{c}\mathrm{C}- \\
\text { terminated }\end{array}$} & W-rich & 7.166 & 6.165 & 6.846 \\
\hline & & C-rich & 6.628 & 5.956 & 6.429 \\
\hline \multirow{6}{*}{$\mathrm{W}_{2} \mathrm{C}$} & \multirow{2}{*}{$\begin{array}{c}\mathrm{W}_{\mathrm{I}^{-}} \\
\text {terminated }\end{array}$} & W-rich & 3.290 & 2.906 & 3.194 \\
\hline & & C-rich & 3.290 & 2.906 & 3.194 \\
\hline & \multirow{2}{*}{$\begin{array}{c}\mathrm{W}_{\mathrm{II}^{-}} \\
\text {terminated }\end{array}$} & W-rich & 4.790 & 4.291 & 4.684 \\
\hline & & C-rich & 4.822 & 4.043 & 4.605 \\
\hline & \multirow{2}{*}{$\begin{array}{c}\mathrm{C}- \\
\text { terminated }\end{array}$} & W-rich & 4.496 & 3.813 & 4.194 \\
\hline & & C-rich & 4.463 & 3.565 & 4.273 \\
\hline \multirow[t]{4}{*}{$\mathrm{Mo}_{2} \mathrm{C}$} & \multirow{2}{*}{$\begin{array}{c}\text { Mo- } \\
\text { terminated }\end{array}$} & Mo-rich & 3.441 & 2.989 & 3.310 \\
\hline & & C-rich & 3.685 & 3.108 & 3.512 \\
\hline & \multirow{2}{*}{$\begin{array}{c}\mathrm{C}- \\
\text { terminated }\end{array}$} & Mo-rich & 4.000 & 3.323 & 3.796 \\
\hline & & C-rich & 3.755 & 3.204 & 3.594 \\
\hline
\end{tabular}


Proof of equivalence of the surface energy expression for a hybrid slab and the standard surface energy expression, along with numerical validation

Figure S1 shows three surface slabs of a pure metal (e.g., Pt) labeled as 1, 2, and 3, respectively. These slabs consist of $\mathrm{M}+2 \mathrm{~N}, \mathrm{M}+2$, and $\mathrm{N}-1$ layers. Following Eq. (2) in the main text, the surface energy of slab 1 can be written as

$$
E_{\text {surf }}^{1}=\frac{1}{2 A_{0}}\left(E_{(\mathrm{M}+2 \mathrm{~N}) \mathrm{L}}^{\mathrm{slab}}-E_{(\mathrm{M}+2 \mathrm{~N}) \mathrm{L}}^{\mathrm{bulk}}\right),
$$

where $E_{(\mathrm{M}+2 \mathrm{~N}) \mathrm{L}}^{\text {slab }}$ refers to the total energy of surface slab 1 with $\mathrm{M}+2 \mathrm{~N}$ layers and $E_{(\mathrm{M}+2 \mathrm{~N}) \mathrm{L}}^{\text {bulk }}$ denotes the total energy of $\mathrm{M}+2 \mathrm{~N}$ layers of metal in bulk. Similarly, the surface energy of slabs 2 and 3 are respectively

$$
E_{\text {surf }}^{2}=\frac{1}{2 A_{0}}\left(E_{(\mathrm{M}+2) \mathrm{L}}^{\text {slab }}-E_{(\mathrm{M}+2) \mathrm{L}}^{\text {bulk }}\right)
$$

and

$$
E_{\text {surf }}^{3}=\frac{1}{2 A_{0}}\left(E_{(N-1) \mathrm{L}}^{\text {slab }}-E_{(N-1) \mathrm{L}}^{\text {bulk }}\right) .
$$

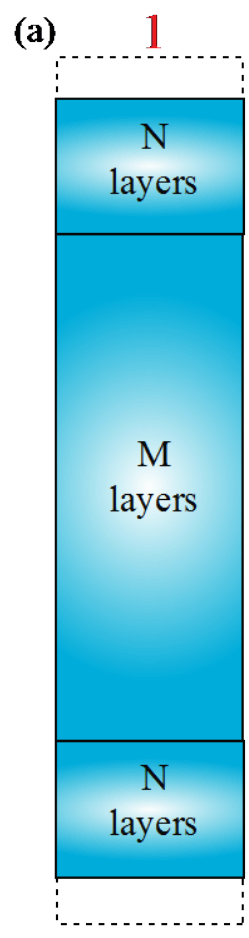

(b)

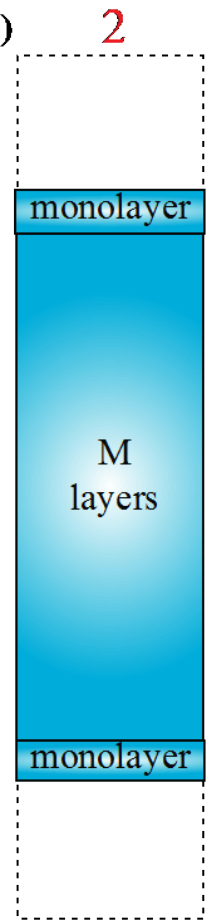

(c)

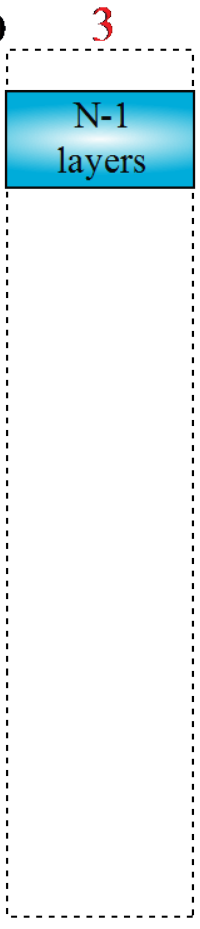

Figure S1. Sketches of surface slabs with (a) M+2N, (b) M+2, and (c) N-1 atomic layers. 
A surface slab of a metal can also be regarded as a slab of a metal monolayer on a metal substrate containing $\mathrm{M}$ layers. Therefore, the surface energy (according to our definition for a hybrid slab given in the main text; see Eq. (12) there) can be written as

$$
E_{\text {surf }}^{\text {hybrid }}=\frac{1}{4 A_{0}}\left(E_{(\mathrm{M}+2) \mathrm{L}}^{\text {slab }}+2 E_{(\mathrm{N}-1) \mathrm{L}}^{\text {slab }}-E_{(\mathrm{M}+2 \mathrm{~N}) \mathrm{L}}^{\text {slab }}\right) .
$$

From Eqs. (S1)-(S3) above, we have

$$
\begin{gathered}
E_{(\mathrm{M}+2 \mathrm{~N}) \mathrm{L}}^{\text {slab }}=2 A_{0} E_{\text {surf }}^{1}+E_{(\mathrm{M}+2 \mathrm{~N}) \mathrm{L}}^{\text {bulk }} \\
E_{(\mathrm{M}+2) \mathrm{L}}^{\text {slab }}=2 A_{0} E_{\text {surf }}^{2}+E_{(\mathrm{M}+2) \mathrm{L}}^{\text {bulk }} \\
E_{(N-1) \mathrm{L}}^{\text {slab }}=2 A_{0} E_{\text {surf }}^{3}+E_{(N-1) \mathrm{L}}^{\text {bulk }} \\
E_{\text {surf }}^{\text {hybrid }}=\frac{1}{4 A_{0}}\left(2 A_{0} E_{\text {surf }}^{2}+E_{(\mathrm{M}+2) \mathrm{L}}^{\text {bulk }}+4 A_{0} E_{\text {surf }}^{3}+2 E_{(N-1) \mathrm{L}}^{\text {bulk }}-2 A_{0} E_{\text {surf }}^{1}-E_{(\mathrm{M}+2 \mathrm{~N}) \mathrm{L}}^{\text {bulk }}\right)
\end{gathered}
$$

Since the bulk energy is an extensive (i.e., additive) quantity,

$$
E_{(\mathrm{M}+2) \mathrm{L}}^{\mathrm{bulk}}+2 E_{(N-1) \mathrm{L}}^{\mathrm{bulk}}-E_{(\mathrm{M}+2 \mathrm{~N}) \mathrm{L}}^{\mathrm{bulk}}=0 .
$$

Therefore,

$$
E_{\text {surf }}^{\text {hybrid }}=\frac{1}{4 A_{0}}\left(2 A_{0} E_{\text {surf }}^{2}+4 A_{0} E_{\text {surf }}^{3}-2 A_{0} E_{\text {surf }}^{1}\right)
$$

If the surfaces slabs of 1,2 , and 3 are sufficiently thick, then

$$
E_{\text {surf }}^{1}=E_{\text {surf }}^{2}=E_{\text {surf }}^{3}=E_{\text {surf }} .
$$

Equation (S4) becomes

$$
E_{\text {surf }}^{\text {hybrid }}=\frac{1}{4 A_{0}}\left(2 A_{0} E_{\text {surf }}^{2}+4 A_{0} E_{\text {surf }}^{3}-2 A_{0} E_{\text {surf }}^{1}\right)=E_{\text {surf }}
$$

i.e., the definition of the surface energy for hybrid surfaces can be reduced to the common definition of the surface energy for pure metals. Table S4 shows that the surface energies of $\mathrm{Au}, \mathrm{Pd}$, and Pt calculated using the definitions in Eq. (S1) and Eq. (S4) are almost the same, which validates Eq. (12) in the main text. 
Table S4. Surface energy $\left(\mathrm{J} / \mathrm{m}^{2}\right)$ of Au, Pd, and Pt obtained with the PBEsol exchange-correlation functional and following the definitions in Eq. (1) and (4).

\begin{tabular}{|c|c|c|c|}
\hline Definition & $\mathrm{Au}$ & $\mathrm{Pd}$ & $\mathrm{Pt}$ \\
\hline Eq. (S1) & 0.976 & 1.675 & 1.806 \\
\hline Eq. (S4) & 0.978 & 1.672 & 1.826 \\
\hline
\end{tabular}


Electrostatic potential profiles of the WC (0001) surface

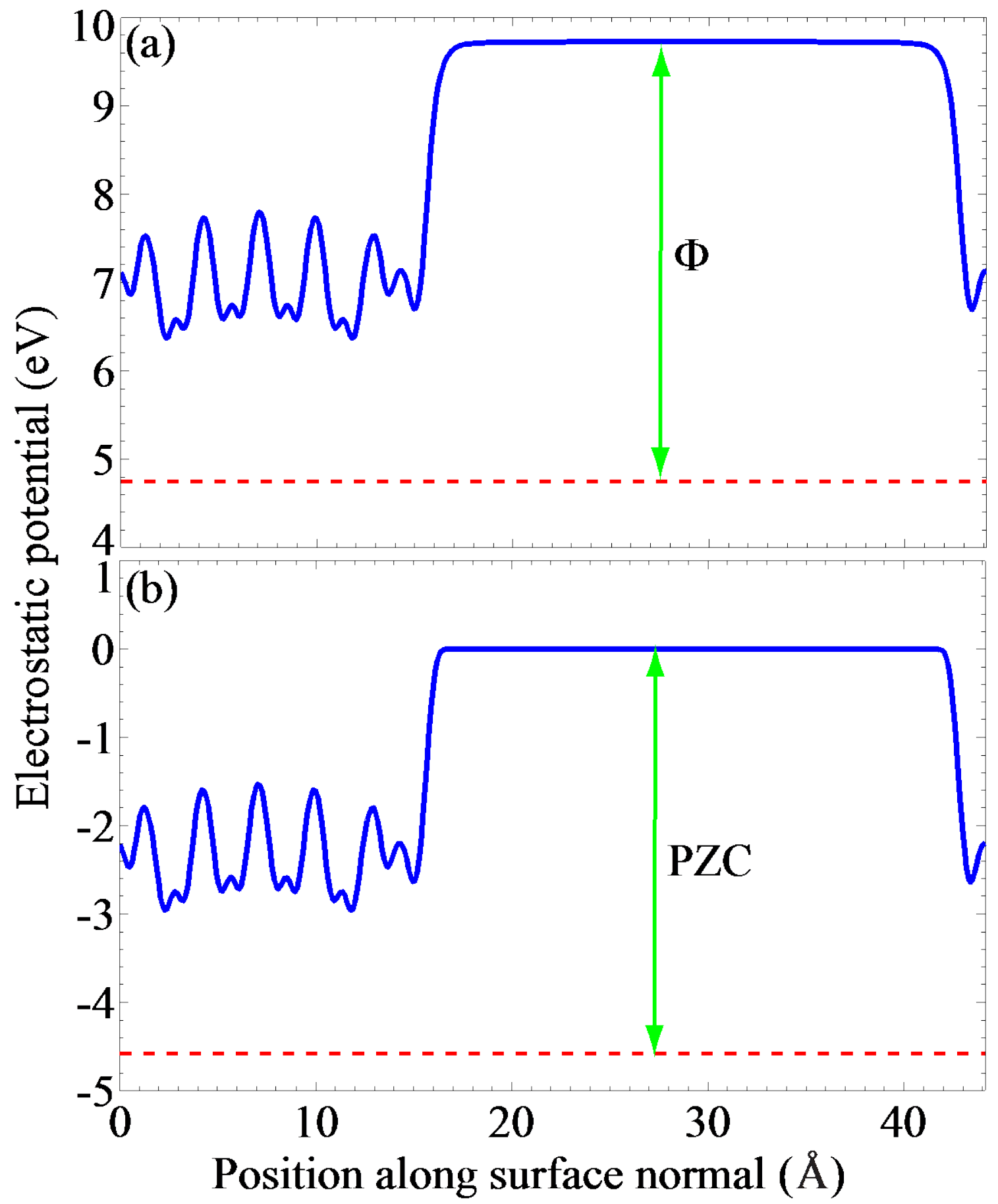

Figure S2. Electrostatic potential profiles of the WC (0001) surface in (a) vacuum and (b) a solution with 1 M monovalent ions. The red dashed lines denote the Fermi levels in the two cases and the green doubleheaded arrows represent the magnitudes of the work function $\Phi$ and PZC. 